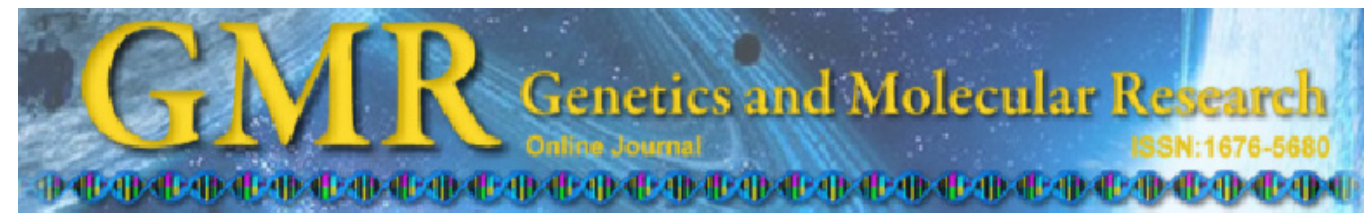

Short Communication

\title{
Genetic data for 15 STR loci in a Kadazan-Dusun population from East Malaysia
}

\author{
B.P. Kee', L.H. Lian' ${ }^{1}$ P.C. Lee ${ }^{2}$, T.X. Lai ${ }^{2}$ and K.H. Chua ${ }^{1}$ \\ ${ }^{1}$ Department of Molecular Medicine, Faculty of Medicine, \\ University of Malaya, Kuala Lumpur, Malaysia \\ ${ }^{2}$ Biotechnology Program, School of Science and Technology, \\ Universiti Sabah Malaysia, Kota Kinabalu, Sabah, Malaysia \\ Corresponding author: L.H. Lian \\ E-mail: 1hlian@um.edu.my
}

Genet. Mol. Res. 10 (2): 739-743 (2011)

Received September 15, 2010

Accepted November 25, 2010

Published April 26, 2011

DOI 10.4238/vol10-2gmr1064

\begin{abstract}
Allele frequencies of 15 short tandem repeat (STR) loci, namely D5S818, D7S820, D13S317, D16S539, TH01, TPOX, Penta D, Penta E, D3S1358, D8S1179, D18S51, D21S11, CSF1PO, vWA, and FGA, were determined for 154 individuals from the Kadazan-Dusun tribe, an indigenous population of East Malaysia. All loci were amplified by polymerase chain reaction, using the Powerplex 16 system. Alleles were typed using a gene analyzer and the Genemapper ID software. Various statistical parameters were calculated and the combined power of discrimination for the 15 loci in the population was calculated as 0.999999999999999. These loci are thus, informative and can be used effectively in forensic and genetic studies of this indigenous population.
\end{abstract}

Key words: Short tandem repeats; Population data; East Malaysia; Powerplex 16 system 


\section{INTRODUCTION}

Short tandem repeats (STR) have been widely used in different aspects of modern scientific research, such as human evolution, forensics, anthropology, and disease development (Calafell et al., 1998; Blessmann et al., 2008; Divine et al., 2010; Lewis Jr., 2010). Therefore, it is important to profile the STRs for local populations, which are helpful for further genetic characterization. Sabah is the second largest State in Malaysia, and is located at the northern pole of Borneo Island (Figure 1). There are approximately 28 indigenous groups that account for $60 \%$ of the local population. Among them, the Kadazan-Dusun tribe is the largest group, which makes up $18 \%$ of the total population. Their origins are still debated until today. The settlement of Island Southeast Asia (ISEA) by modern humans was described by researchers with the "Out of Taiwan" model (Bellwood, 2007). The dispersal was believed to occur in two tiers - the first tier was marked by the arrival of "Australo-Melanesian" about 50,000 years ago. This was followed by the colonization by "Autronesians", who came by sea from Southern China through Taiwan, about 5000 years ago for agricultural purposes (Bellwood, 2007). Hence, in the present study, we examined 15 STR loci in the Kadazan-Dusun population. To the best of our knowledge, this is the first report of population data with regard to the STRs of this indigenous tribe from East Malaysia.

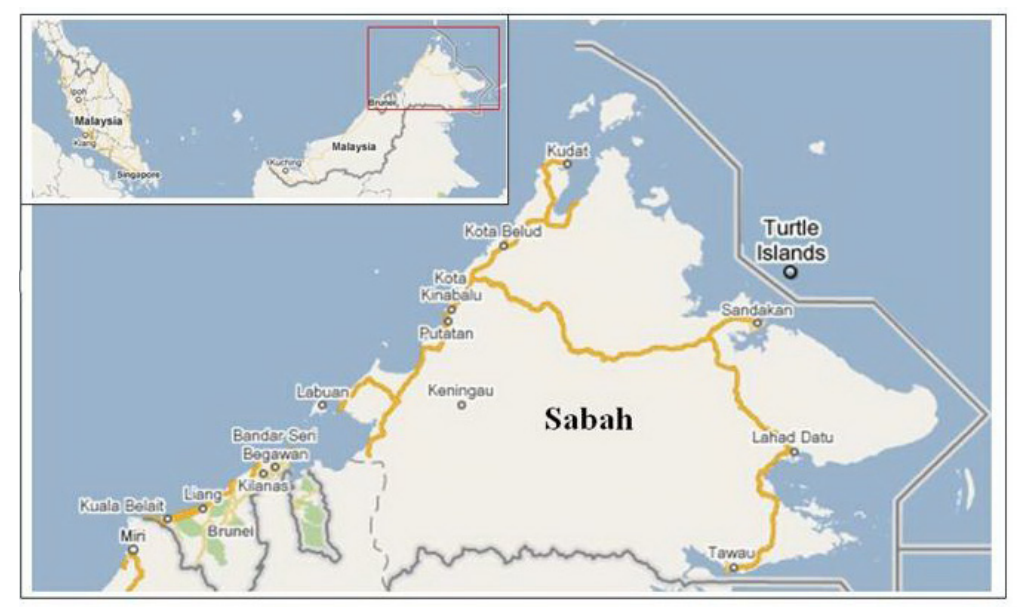

Figure 1. Location of the Sabah State, East Malaysia (Source: edited from Google Maps).

\section{MATERIAL AND METHODS}

One hundred and fifty-four unrelated healthy individuals from the Kadazan-Dusun tribe residing in the State of Sabah in East Malaysia were randomly sampled. Ethical approval for the project was obtained from the University of Malaya Medical Centre's Medical Ethics Committee (No. 770.21), which operates according to the ICH-GCP guidelines and the Declaration of Helsinki. Genomic DNA was extracted from peripheral blood samples via a modified conventional phenol-chloroform extraction method. The quality and quantity of the extracted DNA was assessed spectrophotometrically. The amplification process was carried out using the Promega Powerplex 16 system according to the cycling parameters recommended by the manufacturer. Amplified products were resolved by native $2 \%(\mathrm{w} / \mathrm{v})$ agarose gel electrophoresis to ensure suc- 
cessful amplification of the desired loci. Typing was performed by capillary electrophoresis using an ABI3100 genetic analyzer. Allelic call and genotyping were carried out via the Genemapper ID software version $3.2(\mathrm{ABI})$, by referring to the allelic ladder included in the kit.

Quality assurance of the test was conducted via laboratory internal controls and kit DNA controls. Allelic frequencies, the observed heterozygosity, power of discrimination, power of exclusion, and polymorphism information content (PIC) were calculated using PowerStats V1.2 (http://www.promega.com) (Tereba, 1999). The estimation of Hardy-Weinberg equilibrium (HWE) and expected heterozygosity was done with the exact test using the Arlequin V3.1 software (Schneider et al., 2000). The level of significance of the exact test was set at $5 \%$.

\section{RESULTS AND DISCUSSION}

Allelic frequencies and statistical parameters of the 15 STR loci examined in this study are shown in Tables 1 and 2 . All loci showed a high degree of heterozygosity $(>0.7)$, with exception of loci D7S820 and TPOX (0.623 and 0.526, respectively). The loci were observed to have high discriminating power, as the power of discrimination of each loci varied from 0.721 (TPOX) to 0.968 (Penta E), whereas the PIC ranged from 0.464 (TPOX) to 0868 (Penta E). The combined power of discrimination for the 15 STR loci studied is 0.999999999999999 . All loci were found to show no deviation from HWE $(\mathrm{P}>0.05)$. In terms of gene diversity, the Penta $\mathrm{E}$ locus was identified as the most polymorphic marker in the Kadazan-Dusun population, with $89.6 \%$ heterozygosity. In our study, the 15 STR loci exhibited high levels of polymorphism in the Kadazan-Dusun population. Therefore, these loci can be used effectively as genetic markers for forensic identification purposes and in various other genetics-based studies.

\begin{tabular}{|c|c|c|c|c|c|c|c|c|}
\hline Allele & D5S818 & D7S820 & D13S317 & D16S539 & TH01 & TPOX & Penta D & Penta E \\
\hline 23 & & & & & & & & 0.023 \\
\hline 22 & & & & & & & & 0.010 \\
\hline 21 & & & & & & & & 0.026 \\
\hline & & & & & & & & 0.007 \\
\hline 19 & & & & & & & & 0.026 \\
\hline 18 & & & & & & & & 0.065 \\
\hline 17 & & & & & & & & 0.078 \\
\hline 16 & & & & & & & & 0.049 \\
\hline & & & & & & & & 0.231 \\
\hline 14 & 0.003 & 0.010 & & 0.010 & & & & 0.068 \\
\hline 13 & 0.068 & 0.007 & & 0.052 & & & 0.208 & 0.023 \\
\hline 12 & 0.172 & 0.136 & 0.247 & 0.114 & & 0.003 & 0.127 & 0.084 \\
\hline 11 & 0.393 & 0.539 & 0.412 & 0.312 & & 0.481 & 0.091 & 0.185 \\
\hline 10 & 0.338 & 0.123 & 0.081 & 0.260 & 0.088 & & 0.133 & 0.026 \\
\hline $\begin{array}{l}9.3 \\
9\end{array}$ & 0.026 & 0.020 & 0.036 & 0.253 & $\begin{array}{l}0.046 \\
0.406\end{array}$ & 0.065 & 0.383 & 0.023 \\
\hline 8 & & 0.166 & 0.224 & & 0.166 & 0.451 & 0.055 & \\
\hline 7 & & & & & 0.218 & & 0.003 & \\
\hline 6 & & & & & 0.078 & & & \\
\hline 5 & & & & & & & & 0.075 \\
\hline 4 & & & & & & & & 0.003 \\
\hline Ho & 0.714 & 0.623 & 0.721 & 0.760 & 0.792 & 0.526 & 0.766 & 0.896 \\
\hline $\mathrm{He}$ & 0.699 & 0.650 & 0.713 & 0.758 & 0.747 & 0.563 & 0.768 & 0.882 \\
\hline PD & 0.843 & 0.830 & 0.864 & 0.890 & 0.896 & 0.721 & 0.908 & 0.968 \\
\hline PIC & 0.642 & 0.609 & 0.663 & 0.714 & 0.710 & 0.464 & 0.734 & 0.868 \\
\hline PE & 0.451 & 0.320 & 0.461 & 0.527 & 0.585 & 0.211 & 0.538 & 0.787 \\
\hline$P$ & 0.437 & 0.066 & 0.546 & 0.125 & 0.389 & 0.442 & 0.094 & 0.052 \\
\hline
\end{tabular}

$\mathrm{Ho}=$ observed heterozygosity; $\mathrm{He}=$ expected heterozygosity; $\mathrm{PD}=$ power of discrimination; $\mathrm{PIC}=$ polymorphism information content; $\mathrm{PE}=$ power of exclusion; $\mathrm{P}$ = probability value of the exact test for $\mathrm{HWE}$. 


\begin{tabular}{|c|c|c|c|c|c|c|c|}
\hline Allele & D3S1358 & D8S1179 & D18S51 & D21S11 & CSF1PO & vWA & FGA \\
\hline 34.2 & & & & 0.003 & & & \\
\hline 33.2 & & & & 0.110 & & & \\
\hline 32.2 & & & & 0.140 & & & \\
\hline 32 & & & & 0.023 & & & \\
\hline 31.2 & & & & 0.084 & & & \\
\hline 31 & & & & 0.136 & & & \\
\hline 30.2 & & & & 0.013 & & & \\
\hline 30 & & & & 0.260 & & & \\
\hline 29 & & & & 0.182 & & & \\
\hline 28 & & & & 0.049 & & & \\
\hline 27 & & & & & & & 0.007 \\
\hline 26 & & & & & & & 0.033 \\
\hline 25.2 & & & & & & & 0.003 \\
\hline 25 & & & & & & & 0.088 \\
\hline 24 & & & & & & & 0.107 \\
\hline 23 & & & & & & & 0.140 \\
\hline 22.2 & & & & & & & 0.003 \\
\hline 22 & & & 0.003 & & & & 0.244 \\
\hline 21 & & & & & & & 0.169 \\
\hline 20 & & & & & & 0.029 & 0.107 \\
\hline 19.2 & & & & & & & 0.003 \\
\hline 19 & 0.013 & & 0.055 & & & 0.084 & 0.052 \\
\hline 18.2 & & & & & & & 0.046 \\
\hline 18 & 0.091 & & 0.010 & & & 0.296 & \\
\hline 17 & 0.192 & 0.013 & 0.068 & & & 0.292 & \\
\hline 16 & 0.260 & 0.104 & 0.146 & & & 0.104 & \\
\hline 15 & 0.432 & 0.149 & 0.334 & & & 0.081 & \\
\hline 14 & 0.013 & 0.224 & 0.292 & & & 0.107 & \\
\hline 13 & & 0.289 & 0.02 & & 0.020 & & \\
\hline 12 & & 0.023 & 0.071 & & 0.412 & & \\
\hline 11 & & 0.068 & & & 0.308 & 0.003 & \\
\hline 10 & & 0.127 & & & 0.221 & 0.003 & \\
\hline 9 & & 0.003 & & & 0.039 & & \\
\hline Но & 0.701 & 0.831 & 0.721 & 0.805 & 0.714 & 0.779 & 0.870 \\
\hline $\mathrm{He}$ & 0.703 & 0.814 & 0.771 & 0.842 & 0.686 & 0.793 & 0.859 \\
\hline PD & 0.857 & 0.932 & 0.913 & 0.951 & 0.829 & 0.928 & 0.958 \\
\hline PIC & 0.652 & 0.787 & 0.735 & 0.820 & 0.625 & 0.762 & 0.841 \\
\hline PE & 0.430 & 0.658 & 0.461 & 0.609 & 0.451 & 0.561 & 0.735 \\
\hline$P$ & 0.584 & 0.217 & 0.780 & 0.163 & 0.709 & 0.250 & 0.339 \\
\hline
\end{tabular}

$\mathrm{Ho}=$ observed heterozygosity; $\mathrm{He}=$ expected heterozygosity; $\mathrm{PD}=$ power of discrimination; $\mathrm{PIC}=$ polymorphism information content; $\mathrm{PE}=$ power of exclusion; $\mathrm{P}$ = probability value of the exact test for HWE.

\section{ACKNOWLEDGMENTS}

Research supported by the Ministry of Science, Technology and Innovation, Malaysia (eScience Fund \#12-02-03-2045), the Ministry of Higher Education, Malaysia (FRGS \#FP024/2009), and the University of Malaya (PPP \#PS234/2010A).

\section{REFERENCES}

Bellwood P (2007). Prehistory of the Indo-Malaysian Archipelago. ANU E Press, Australia.

Blessmann M, Kaifi JT, Schurr PG, Cihan A, et al. (2008). Short tandem repeat polymorphism in exon 4 of esophageal cancer related gene 2 predicts relapse of oral squamous cell carcinoma. Oral Oncol. 44: 143-147.

Calafell F, Shuster A, Speed WC, Kidd JR, et al. (1998). Short tandem repeat polymorphism evolution in humans. Eur. J. Hum. Genet. 6: 38-49. 
Divine AM, Edlund H and Allen M (2010). Forensic analysis of autosomal STR markers using pyrosequencing. Forensic Sci. Int-Gen. 4: 122-129.

Lewis CM Jr (2010). Hierarchical modeling of genome-wide short tandem repeat (STR) markers infers native American prehistory. Am. J. Phys. Anthropol. 141: 281-289.

Schneider S, Roessli D and Excoffier L (2000). Arlequin: A Software for Population Genetics Data Analysis. Ver. 2.000. Genetics and Biometry Laboratory, Department of Anthropology, University of Geneva, Geneva.

Tereba A (1999). Tools for Analysis of Population Statistics. Profiles in DNA 2: 14-16. 